$$
\text { Z B Research SQuare }
$$

\title{
Strategies for increasing gait speed in patients with hip osteoarthritis: their clinical significance and effects on hip loading
}

Hiroshige Tateuchi ( $\nabla$ tateuchi.hiroshige.8x@kyoto-u.ac.jp)

Kyoto University https://orcid.org/0000-0002-7429-8204

Haruhiko Akiyama

Gifu University

Koji Goto

Kyoto University

Kazutaka So

Osaka Red Cross Hospital

Yutaka Kuroda

Kyoto University

Noriaki Ichihashi

Kyoto University

Research article

Keywords: Hip osteoarthritis, Gait, Physical function, Pain, Joint moment

Posted Date: August 2nd, 2020

DOI: https://doi.org/10.21203/rs.3.rs-50108/v1

License: (c) (1) This work is licensed under a Creative Commons Attribution 4.0 International License. Read Full License 


\section{Abstract \\ Background}

Change in gait speed is required in various situations in daily life, and can be achieved by changing stride length, cadence, or both. Differences in strategies for increasing gait speed may have different effects on the hip joint and on physical function. Our primary purpose was to determine the effects of strategies for increasing gait speed on hip pain and physical function in patients with hip osteoarthritis (OA). The secondary purpose was to examine the effects of strategies for increasing gait speed on the changes in hip loading during gait.

\section{Methods}

Forty-seven patients with secondary hip OA (age $48.3 \pm 11.0$ years) were included. Gait speed, stride length, cadence, and peak and impulse of the hip joint moment were measured during gait at self-selected normal and fast gait speeds, using a three-dimensional motion analysis system. The patients were classified as types S (increasing mainly stride length), C (increasing mainly cadence), and SC (increasing stride length and cadence) according to whether they used changes in stride length and/or cadence to transition from a normal to a fast gait. Hip pain, physical function, and change in hip moments during gait were compared between the types.

\section{Results}

The distribution of the patients was as follows: types S, 23.4\%; C, 48.9\%; and SC, $27.7 \%$. Physical function status was higher in types C $(P=0.018)$ and SC $(P$ $=0.015)$ than in type $S$, even after adjustment for age and minimum joint space width. Hip pain was not significantly different between the types. The robustness of those results was confirmed by a sensitivity analysis. The rates of the increases in peak external hip adduction $(P=0.003)$ and internal rotation moments $(P=0.009)$ were lower in type $C$ than in type SC.

\section{Conclusions}

Type $C$ tended to suppress the increase in hip joint moments during fast gait. Types $C$ and SC, which included increased cadence, maintained higher physical function levels than type S. Encouraging use of a cadence-increasing strategy may be useful for reducing hip loading and maintaining physical function in patients with hip OA.

\section{Background}

Changes in gait speed are required in various situations in daily life, such as ambulating outdoors, including crosswalks [1]. As gait speed is determined by stride length and cadence, increased gait speed can be due to increased stride length, increased cadence, or a combination of both [2, 3]. In healthy individuals, both stride length and cadence increase linearly with increasing gait speed, regardless of age [2]. This stride length-cadence relationship represents the central control of automatic gait. Moreover, the loading on the lower limb joints can be increased as the gait speed increases [3 - 7]. Increasing stride length rather than cadence causes an increase in peak external joint moment on hip flexion, hip adduction, hip internal rotation, knee flexion, knee adduction, and ankle plantarflexion $[3,4,6,7]$. Therefore, differences in the strategies (i.e., increased stride length, increased cadence, or both) used to change gait speed could alter the loading on the lower limb joints. Given that the difference in the strategy used affects joint loading, understanding the strategies associated with changes in gait speed is important for assisting patients with joint diseases.

A decrease in gait speed mainly by decreasing stride length is a typical characteristic of the spatiotemporal gait parameters in patients with hip osteoarthritis (OA) [8]. Although the stride length and cadence increase as the gait speed increases, even for patients with hip OA as a whole, increases in stride length and cadence in these individuals tend to have a wider data distribution than in healthy individuals [9]. This may indicate variations in strategies to increase gait speed in patients with hip OA. However, little is known about variations in the strategies for increasing gait speed in patients with hip OA.

Differences in the types of strategy for increasing gait speed may change hip joint loading, even with equal increases in gait speed, and consequently, differences in strategies might affect hip joint symptoms and physical function status. However, the relationship between the type of strategy used to increase gait speed revealed by a gait analysis at different speeds and hip pain and physical function levels has not been investigated in individuals with hip OA. Examining the strategies for changes in gait speed can reveal the underlying adjustment mechanism during gait, which is not apparent by observing natural gait alone, and may be useful for maintaining and improving joint pain and physical function.

The primary purpose of this study was to determine the effect of the strategies used to increase gait speed on hip pain and physical function status in patients with hip OA. The secondary purpose was to examine the effects of the types of strategies used for increasing gait speed on hip loading during gait. We hypothesized that the patients who increase gait speed mainly by increasing cadence would have less hip pain, a higher physical function level, and a lower rate of increase in hip joint moments with increasing gait speed.

\section{Methods}

\section{Participants}


Fifty-two female patients with secondary hip OA (age: $47.8 \pm 10.7$ years) were consecutively recruited for this study. The patients were enrolled from among patients who attended the Department of Orthopedic surgery of a university hospital continuously from April 2013 to March 2015 . The inclusion criteria were as follows: patients aged 20-65 years, who had secondary hip OA, and were able to walk without any assistive device in daily life. The exclusion criteria were as follows: patients with a history of previous hip surgery (e.g., osteotomy and arthroplasty), and neurological, vascular, or other conditions that affected gait. The distribution of the patients among the hip OA stages [10] was as follows: pre-OA $(n=15,28.8 \%)$, early-OA $(n=25,48.1 \%)$, and advanced-OA stages $(n=$ $12,23.1 \%)$. The side with more severe radiographic OA change was used in the analysis. Written informed consent was obtained from all the patients, and this study was approved by the institutional review board.

\section{Gait analysis}

The participants wore body-fitting T-shirts and short spats. Twenty-six reflective markers were placed at various points on their body by a single experienced examiner. Each body segment was composed of the following marker sets: the trunk, consisting of the seventh cervical spinous process, the tenth thoracic spinous process, the jugular notch, the xiphoid process, and the bilateral acromioclavicular joints; the pelvis, consisting of the bilateral anterior and posterior superior iliac spine; the thigh, consisting of the superior aspect of the greater trochanter, and the medial and lateral femoral condyles; the shank, consisting of the medial and lateral femoral condyles, and the medial and lateral malleoli; and the foot, consisting of the heel, the head of the first and fifth metatarsal, and the medial and lateral malleoli. The marker position $(200 \mathrm{~Hz})$ and the ground reaction forces $(1000 \mathrm{~Hz})$ were collected using an 8-camera Vicon motion system (Vicon Motion Systems Ltd., Oxford, England) and force plates (Kistler Japan Co., Ltd., Tokyo, Japan). The marker position data and ground reaction force data were filtered using a fourth-order Butterworth low-pass filter at 6 and $20 \mathrm{~Hz}$, respectively. Gait speed, stride length, cadence, and external hip joint moments were computed using Vicon Nexus and BodyBuilder (Vicon Motion Systems Ltd., Oxford, England) [11]. The external hip moment peak in each of the 3 planes and the hip moment impulse (timed integral of the hip joint moment) in each of the 3 planes were calculated as indexes of hip joint loading. The hip joint moment was normalized to body weight and height ( $\mathrm{Nm} / \mathrm{kgm})$. Stride length was expressed as a percentage of leg length (distance between the anterior superior iliac spine and medial malleolus). The mean values of the gait variables from the 3 trials were used in the analysis.

All the participants practiced normal and fast gaits several times to familiarize themselves with the experimental environment prior to data recording. At least 3 trials were recorded for each of the barefoot gaits at self-selected normal (normal gait) and fast speeds (fast gait). By adjusting the start position, gait trials in which the feet properly contacted the force plates, without making the participants aware of the position of the force plates, were secured.

The types of strategies for increasing gait speed were classified on the basis of the average stride length and cadence of 3 trials each for normal and fast gait, as described in a previous study [3]. First, the rates of increases in stride length and cadence were calculated, and then the ratio of the rate of increase in cadence to the rate of increase in stride length was computed. For the ratio, a value $<0.75$ was defined as type $S$ (i.e., increase mainly stride length), a value $\geq$ 1.55 as type $C$ (i.e., increase mainly cadence), and a value $\geq 0.75$ but $<1.55$ as type SC (i.e., increase both stride length and cadence; Figure 1 ). Participants with $<5 \%$ increase in gait speed during fast gait as compared to normal gait were excluded from the analysis.

\section{Assessment of hip pain and physical function}

The average pain intensity at the hip joint during daily life in the last 3 months was assessed on a 100-mm visual analog scale. Physical function was assessed using the physical component summary of the Japanese version of the Medical Outcomes Study 36-Item Short-Form Health Survey (SF-36) version 2.0. The SF-36 is the tool most commonly used to assess health status in the general population, and has been used for patients with OA with high reliability and validity $[12,13]$.

\section{Assessment of joint space narrowing and hip impairments}

A digital supine anteroposterior radiograph of the pelvis was obtained in a standardized manner by skilled radiology technicians. To assess the degree of cartilage degeneration and severity of hip OA, the minimum joint space width (mJSW) was measured digitally on the radiograph by a single examiner, using Centricity Enterprise Web, version 3.0 (GE Healthcare, Little Chalfont, England). The mJSW had the highest level of intra- and inter-rater reliabilities and good applicability as a parameter for hip OA diagnosis [14]. mJSW was measured at the vertex and medial and lateral sides of the weight-bearing surface, and if a minimum distance was present at a position other than those 3 locations, it was also measured as a fourth measurement [15]. The minimum value for 3 or 4 locations was defined as the mJSW $[15,16]$. The intra-rater reliability (ICC 1,1$)$ of the mJSW measurement was 0.99 [16].

Hip range-of-motion (ROM) and muscle strength were assessed by a single experienced examiner as previously reported [17,18]. The passive ROM of the hip joint was measured at flexion, extension, and abduction, using a standard two-arm goniometer (Sakai Medical Co., Ltd, Tokyo, Japan). The intra-rater reliability (ICC 1,1$)$ of the ROM measurements ranged from 0.82 to 0.98 [18]. The maximal isometric muscle strengths on hip flexion, extension, and abduction were measured using a handheld dynamometer ( $\mu$ TAS F-1; Anima Co., Ltd, Tokyo, Japan). Muscle strength was measured twice, and the mean of the measurements from the 2 trials was used in the analysis. The intra-rater reliability (ICC 1,1) for the muscle strength measurements ranged from 0.93 to 0.96 [18]. Muscle strength was normalized to the body weight $(\mathrm{Nm} / \mathrm{kg})$.

\section{Statistical analyses}

Differences in hip pain severity and physical function status, main outcome measures, demographic characteristics, mJSW, hip ROM, and hip muscle strength were tested using an unpaired $t$-test with Holm correction. Furthermore, as hip pain and physical function could be influenced by aging and OA severity [19-21], comparisons of these variables were also performed with adjustment for age and mJSW using a general linear model. A sensitivity analysis was also performed to evaluate the robustness of the type classification and the results of comparison of hip pain and physical function among types. Changes in gait speed, stride length, cadence, and hip joint moment were tested using the analysis of variance for split-pot factorial design (type $\times$ speed). We also calculated effect size in terms of Cohen's $d$ and $f$ using GPower 3.1.7 (Heinrich-Heine-Universität Düsseldorf, Düsseldorf, Germany). Cohen's $d$ values of 0.20, 0.50, and 
0.80 , and Cohen's $f$ values of $0.10,0.25$, and 0.40 indicate small, moderate, and large effects, respectively [22]. SPSS version 26.0 (IBM Japan Ltd., Tokyo, Japan) was used for the statistical analysis. The significance level was set at $P<0.05$.

\section{Results}

Five patients failed to achieve a gait speed change of $>5 \%$ from normal to fast gait and were thus excluded from further analysis. The remaining 47 patients were included in the analysis.

\section{Classification of the strategies for increasing gait speed}

The distribution of the types of strategy was as follows: type S, 11 (23.4\%); type C, 23 (48.9\%); and type SC, 13 (27.7\%). Four patients were of type C, with a negative increase rate in stride length (i.e., stride length decreased in fast gait compared with normal gait), despite a significantly increased gait speed. The patients' characteristics according to strategy type are shown in Table 1. Only hip flexion ROM was significantly larger in type $\mathrm{C}$ than in type S.

Table 1

Basic characteristics in each strategy type

\begin{tabular}{|c|c|c|c|}
\hline & $\begin{array}{l}\text { Type S } \\
(n=11)\end{array}$ & $\begin{array}{l}\text { Type C } \\
(n=23)\end{array}$ & $\begin{array}{l}\text { Type SC } \\
(n=13)\end{array}$ \\
\hline Age, years & $52.3 \pm 10.3$ & $47.4 \pm 11.6$ & $46.5 \pm 10.5$ \\
\hline Height, cm & $155.9 \pm 5.0$ & $158.8 \pm 6.9$ & $156.1 \pm 2.5$ \\
\hline Body weight, kg & $54.9 \pm 8.1$ & $55.3 \pm 8.9$ & $52.0 \pm 8.7$ \\
\hline Body mass index, $\mathrm{kg} / \mathrm{m}^{2}$ & $22.7 \pm 3.7$ & $22.0 \pm 3.5$ & $21.3 \pm 3.3$ \\
\hline Minimum JSW, mm & $2.9 \pm 1.7$ & $3.3 \pm 1.4$ & $3.5 \pm 1.2$ \\
\hline \multicolumn{4}{|l|}{ Passive Hip ROM, degrees } \\
\hline Flexion & $103.0 \pm 15.0$ & $118.1 \pm 10.1$ * & $114.0 \pm 13.4$ \\
\hline Extension & $10.1 \pm 3.2$ & $12.7 \pm 2.9$ & $11.2 \pm 3.3$ \\
\hline Abduction & $20.8 \pm 5.7$ & $24.8 \pm 5.0$ & $24.5 \pm 6.8$ \\
\hline \multicolumn{4}{|l|}{ Hip muscle strength, $\mathrm{Nm} / \mathrm{kg}$} \\
\hline Flexion & $0.77 \pm 0.17$ & $0.97 \pm 0.27$ & $0.86 \pm 0.24$ \\
\hline Extension & $1.33 \pm 0.21$ & $1.69 \pm 0.61$ & $1.48 \pm 0.59$ \\
\hline Abduction & $0.74 \pm 0.08$ & $0.82 \pm 0.23$ & $0.75 \pm 0.21$ \\
\hline \multicolumn{4}{|l|}{ (Footnotes for Table 1) } \\
\hline \multicolumn{4}{|c|}{ Values are mean \pm standard deviation. JSW = joint space width. ROM = range of motion. } \\
\hline \multicolumn{4}{|c|}{$\star$ : Difference compared with type S ( $P=0.003$, effect size $d=1.18)$. } \\
\hline
\end{tabular}

\section{Comparison of hip pain and physical function according to strategy type}

Hip pain and physical function status according to strategy type are described in Table 2. Hip pain was not statistically significantly different between the strategy types. The physical function score was statistically significantly higher in types $\mathrm{C}$ and SC than in type S; this difference remained even after adjustment for age and mJSW. Statistically significant differences in physical function among types persisted in sensitivity analyses using different criteria for type classification (Table 3), indicating the robustness of the results. 
Table 2

Hip pain and physical function in each strategy type and comparison between strategy types

\begin{tabular}{|c|c|c|c|c|c|}
\hline & $\begin{array}{l}\text { Type S } \\
(n=11)\end{array}$ & $\begin{array}{l}\text { Type C } \\
(n=23)\end{array}$ & $\begin{array}{l}\text { Type SC } \\
(n=13)\end{array}$ & $P$-value* (effect size, $f$ ) & $\begin{array}{l}P \text {-value* adjusted for } \\
\text { age and mJSW (effect size, } f \text { ) }\end{array}$ \\
\hline \multirow[t]{3}{*}{ Hip pain (VAS), mm } & \multirow{3}{*}{$\begin{array}{l}57.0 \pm \\
23.5\end{array}$} & \multirow{3}{*}{$\begin{array}{l}42.8 \pm \\
26.7\end{array}$} & \multirow[t]{3}{*}{$35.5 \pm 26.9$} & S vs C: $0.284(0.27)$ & S vs C: $0.502(0.21)$ \\
\hline & & & & C vs SC: $0.436(0.14)$ & C vs SC: $0.524(0.11)$ \\
\hline & & & & S vs SC: $0.150(0.44)$ & S vs SC: $0.312(0.38)$ \\
\hline \multirow[t]{3}{*}{ Physical function (PCS in SF-36), point } & \multirow[t]{3}{*}{$28.2 \pm 7.8$} & \multirow[t]{3}{*}{$38.0 \pm 8.8$} & \multirow[t]{3}{*}{$40.6 \pm 8.5$} & S vs C: $0.006(0.56)$ & S vs C: $0.018(0.51)$ \\
\hline & & & & C vs SC: $0.398(0.15)$ & C vs SC: $0.464(0.13)$ \\
\hline & & & & S vs SC: $0.003(0.79)$ & S vs SC: $0.015(0.71)$ \\
\hline (Footnotes for Table 2) & & & & & \\
\hline
\end{tabular}

Table 3

Sensitivity analyses of comparison between strategy types in hip pain and physical function

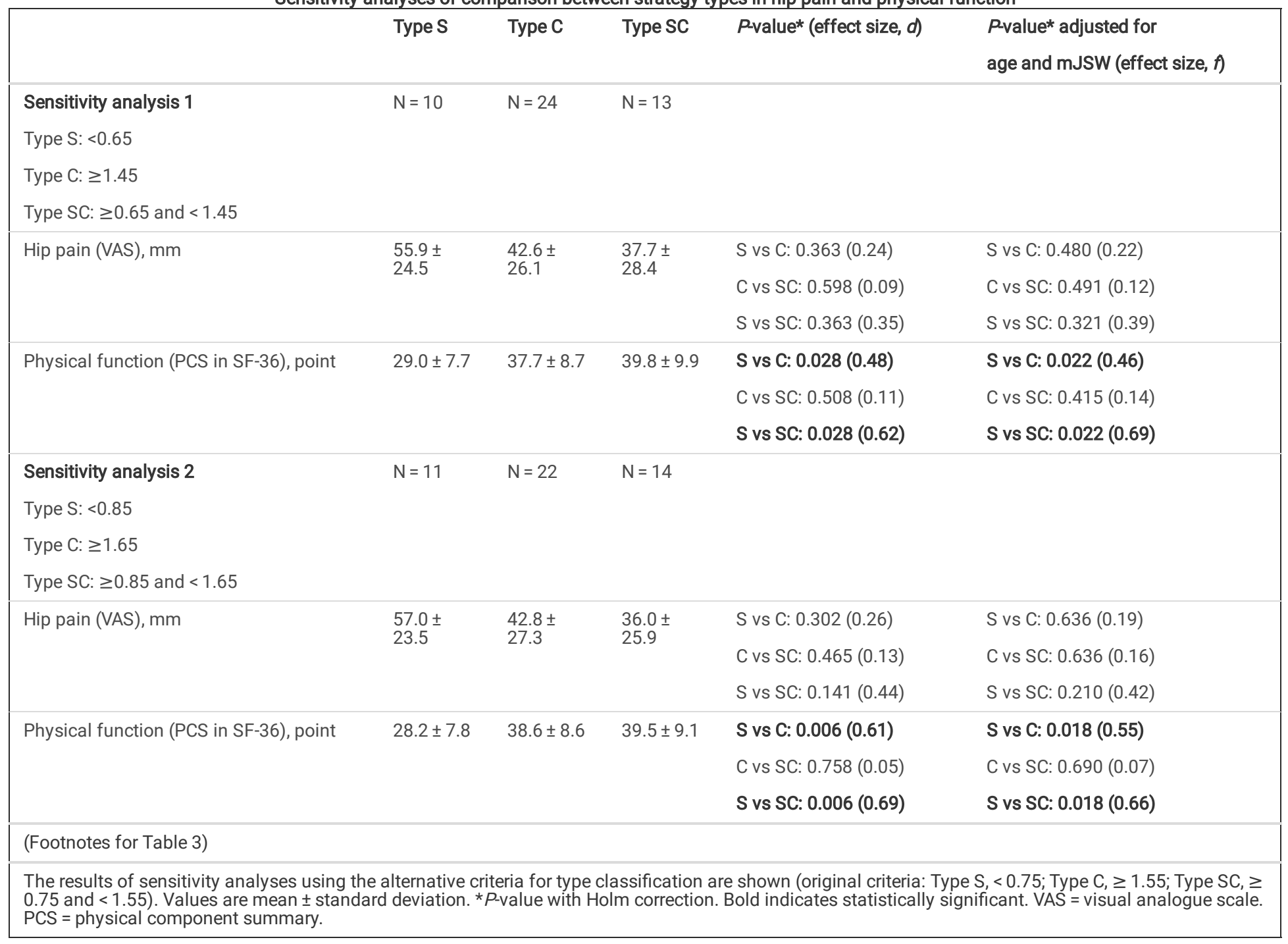


Comparison of changes in gait biomechanics according to strategy type

The changes in gait biomechanics according to strategy type are shown in Table 4. No statistically significant differences among types in terms of gait speed, stride length, and cadence were found during normal gait $(P=0.237-0.880)$. Gait speed was increased in all types, and there was no main effect of type or interaction effect. Both stride length and cadence had a main effect of speed and an interaction effect. Although both stride length and cadence increased significantly in fast gait as compared with normal gait in all types, the rate of increase in stride length was significantly lower for type $\mathrm{C}$ than for types $\mathrm{S}$ and SC, and that in cadence was lower for type S than for types $\mathrm{C}$ and SC. 
Table 4

Changes in gait biomechanics in each strategy type and comparison between strategy types

\begin{tabular}{|c|c|c|c|c|c|c|c|c|c|c|c|c|}
\hline & \multicolumn{3}{|c|}{ Type $S(n=11)$} & \multicolumn{3}{|c|}{ Type C $(n=23)$} & \multicolumn{3}{|c|}{ Type SC $(n=13)$} & \multicolumn{3}{|c|}{$P$-value (effect size, $f$ ) } \\
\hline & Normal & Fast & $\begin{array}{l}\text { Change } \\
(\%)\end{array}$ & Normal & Fast & $\begin{array}{l}\text { Change } \\
(\%)\end{array}$ & Normal & Fast & $\begin{array}{l}\text { Change } \\
(\%)\end{array}$ & Type & Speed & Interac \\
\hline Gait speed, m/sec. & $\begin{array}{l}1.13 \pm \\
0.10\end{array}$ & $\begin{array}{l}1.31 \\
\pm 0.13\end{array}$ & $\begin{array}{l}15.6 \pm \\
6.9\end{array}$ & $\begin{array}{l}1.19 \pm \\
0.15\end{array}$ & $\begin{array}{l}1.36 \\
\pm 0.14\end{array}$ & $\begin{array}{l}15.2 \pm \\
7.9\end{array}$ & $\begin{array}{l}1.10 \pm \\
0.16\end{array}$ & $\begin{array}{l}1.31 \\
\pm 0.18\end{array}$ & $\begin{array}{l}19.6 \pm \\
7.4\end{array}$ & $\begin{array}{l}0.298 \\
(0.24)\end{array}$ & $\begin{array}{l}<.001 \\
(2.34)\end{array}$ & $\begin{array}{l}0.348 \\
(0.22)\end{array}$ \\
\hline $\begin{array}{l}\text { Stride length, (\% leg } \\
\text { length) }\end{array}$ & $\begin{array}{l}147.2 \\
\pm 9.8\end{array}$ & $\begin{array}{l}163.5 \\
\pm 17.2\end{array}$ & $\begin{array}{l}10.9 \pm \\
7.4\end{array}$ & $\begin{array}{l}153.9 \\
\pm 10.1\end{array}$ & $\begin{array}{l}157.4 \\
\pm 10.2\end{array}$ & $2.3 \pm$ & $\begin{array}{l}145.8 \\
\pm 13.9\end{array}$ & $\begin{array}{l}158.1 \\
\pm 14.6\end{array}$ & $\begin{array}{l}8.5 \pm \\
2.8\end{array}$ & $\begin{array}{l}0.651 \\
(0.14)\end{array}$ & $\begin{array}{l}<.001 \\
(1.64)\end{array}$ & $\begin{array}{l}<0.00 \\
(0.89)\end{array}$ \\
\hline Cadence, steps/min. & $\begin{array}{l}120.4 \\
\pm 8.5\end{array}$ & $\begin{array}{l}126.4 \\
\pm 12.8\end{array}$ & $\begin{array}{l}4.8 \pm \\
5.0 \dagger\end{array}$ & $\begin{array}{l}117.0 \\
\pm 8.8\end{array}$ & $\begin{array}{l}131.4 \\
\pm 10.4\end{array}$ & $\begin{array}{l}12.4 \pm \\
6.3\end{array}$ & $\begin{array}{l}117.5 \\
\pm 11.2\end{array}$ & $\begin{array}{l}129.4 \\
\pm 11.4\end{array}$ & $\begin{array}{l}10.2 \pm \\
4.2\end{array}$ & $\begin{array}{l}0.966 \\
(0.04)\end{array}$ & $\begin{array}{l}<.001 \\
(1.72)\end{array}$ & $\begin{array}{l}0.002 \\
(0.57)\end{array}$ \\
\hline
\end{tabular}

Hip moment (peak),

$\mathrm{Nm} / \mathrm{kgm}$

\begin{tabular}{|c|c|c|c|c|c|c|c|c|c|c|c|c|}
\hline Flexion & $\begin{array}{l}0.47 \pm \\
0.11\end{array}$ & $\begin{array}{l}0.72 \\
\pm 0.25\end{array}$ & $\begin{array}{l}53.8 \pm \\
37.0\end{array}$ & $\begin{array}{l}0.49 \pm \\
0.11\end{array}$ & $\begin{array}{l}0.68 \\
\pm 0.16\end{array}$ & $\begin{array}{l}44.5 \pm \\
32.9\end{array}$ & $\begin{array}{l}0.44 \pm \\
0.12\end{array}$ & $\begin{array}{l}0.63 \\
\pm 0.22\end{array}$ & $\begin{array}{l}43.5 \pm \\
32.5\end{array}$ & $\begin{array}{l}0.469 \\
(0.19)\end{array}$ & $\begin{array}{l}<.001 \\
(1.28)\end{array}$ & $\begin{array}{l}0.587 \\
(0.16)\end{array}$ \\
\hline Extension & $\begin{array}{l}0.30 \pm \\
0.10\end{array}$ & $\begin{array}{l}0.35 \\
\pm 0.09\end{array}$ & $\begin{array}{l}19.8 \pm \\
13.1\end{array}$ & $\begin{array}{l}0.31 \pm \\
0.09\end{array}$ & $\begin{array}{l}0.38 \\
\pm 0.08\end{array}$ & $\begin{array}{l}28.0 \pm \\
22.0\end{array}$ & $\begin{array}{l}0.30 \pm \\
0.09\end{array}$ & $\begin{array}{l}0.38 \\
\pm 0.10\end{array}$ & $\begin{array}{l}30.7 \pm \\
21.5\end{array}$ & $\begin{array}{l}0.889 \\
(0.07)\end{array}$ & $\begin{array}{l}< \\
0.001 \\
(1.54)\end{array}$ & $\begin{array}{l}0.177 \\
(0.29)\end{array}$ \\
\hline Adduction & $\begin{array}{l}0.65 \pm \\
0.11\end{array}$ & $\begin{array}{l}0.69 \\
\pm 0.10\end{array}$ & $\begin{array}{l}6.8 \pm \\
6.7\end{array}$ & $\begin{array}{l}0.70 \pm \\
0.13\end{array}$ & $\begin{array}{l}0.73 \\
\pm 0.13\end{array}$ & $\begin{array}{l}4.2 \pm \\
7.1 \neq\end{array}$ & $\begin{array}{l}0.65 \pm \\
0.10\end{array}$ & $\begin{array}{l}0.73 \\
\pm 0.11\end{array}$ & $\begin{array}{l}13.6 \pm \\
8.0\end{array}$ & $\begin{array}{l}0.581 \\
(0.16)\end{array}$ & $\begin{array}{l}<.001 \\
(1.10)\end{array}$ & $\begin{array}{l}0.002 \\
(0.56)\end{array}$ \\
\hline Internal rotation & $\begin{array}{l}0.09 \pm \\
0.04\end{array}$ & $\begin{array}{l}0.12 \\
\pm 0.04\end{array}$ & $\begin{array}{l}34.7 \pm \\
35.7\end{array}$ & $\begin{array}{l}0.12 \pm \\
0.04\end{array}$ & $\begin{array}{l}0.14 \\
\pm 0.04\end{array}$ & $\begin{array}{l}19.1 \pm \\
19.9 \ddagger\end{array}$ & $\begin{array}{l}0.10 \pm \\
0.04\end{array}$ & $\begin{array}{l}0.14 \\
\pm 0.04\end{array}$ & $\begin{array}{l}47.8 \pm \\
34.5\end{array}$ & $\begin{array}{l}0.284 \\
(0.24)\end{array}$ & $\begin{array}{l}<.001 \\
(1.47)\end{array}$ & $\begin{array}{l}0.021 \\
(0.44)\end{array}$ \\
\hline External rotation & $\begin{array}{l}0.07 \pm \\
0.02\end{array}$ & $\begin{array}{l}0.07 \\
\pm 0.03\end{array}$ & $\begin{array}{l}3.9 \pm \\
16.5\end{array}$ & $\begin{array}{l}0.07 \pm \\
0.03\end{array}$ & $\begin{array}{l}0.08 \\
\pm 0.03\end{array}$ & $\begin{array}{l}7.1 \pm \\
20.0\end{array}$ & $\begin{array}{l}0.09 \pm \\
0.02\end{array}$ & $\begin{array}{l}0.10 \\
\pm 0.03\end{array}$ & $\begin{array}{l}8.9 \pm \\
26.1\end{array}$ & $\begin{array}{l}0.130 \\
(0.38)\end{array}$ & $\begin{array}{l}0.020 \\
(0.36)\end{array}$ & $\begin{array}{l}0.786 \\
(0.11)\end{array}$ \\
\hline
\end{tabular}

Hip moment

(impulse),

$\mathrm{Nms} / \mathrm{kgm}$

\begin{tabular}{|c|c|c|c|c|c|c|c|c|c|c|c|c|}
\hline Flexion/Extension & $\begin{array}{l}0.09 \pm \\
0.02\end{array}$ & $\begin{array}{l}0.10 \\
\pm 0.02\end{array}$ & $\begin{array}{l}3.2 \pm \\
12.7\end{array}$ & $\begin{array}{l}0.11 \pm \\
0.03\end{array}$ & $\begin{array}{l}0.11 \\
\pm 0.02\end{array}$ & $\begin{array}{l}2.3 \pm \\
9.2\end{array}$ & $\begin{array}{l}0.09 \pm \\
0.02\end{array}$ & $\begin{array}{l}0.10 \\
\pm 0.02\end{array}$ & $\begin{array}{l}4.1 \pm \\
10.2\end{array}$ & $\begin{array}{l}0.213 \\
(0.27)\end{array}$ & $\begin{array}{l}0.334 \\
(0.15)\end{array}$ & $\begin{array}{l}0.843 \\
(0.09)\end{array}$ \\
\hline Abduction/Adduction & $\begin{array}{l}0.25 \pm \\
0.05\end{array}$ & $\begin{array}{l}0.24 \\
\pm 0.05\end{array}$ & $\begin{array}{l}-7.2 \pm \\
5.2\end{array}$ & $\begin{array}{l}0.27 \pm \\
0.05\end{array}$ & $\begin{array}{l}0.24 \\
\pm 0.05\end{array}$ & $\begin{array}{l}-11.9 \\
\pm 6.9\end{array}$ & $\begin{array}{l}0.26 \pm \\
0.06\end{array}$ & $\begin{array}{l}0.23 \\
\pm 0.06\end{array}$ & $\begin{array}{l}-10.9 \\
\pm 5.1\end{array}$ & $\begin{array}{l}0.912 \\
(0.06)\end{array}$ & $\begin{array}{l}<.001 \\
(1.60)\end{array}$ & $\begin{array}{l}0.068 \\
(0.36)\end{array}$ \\
\hline $\begin{array}{l}\text { External/Internal } \\
\text { rotation }\end{array}$ & $\begin{array}{l}0.03 \pm \\
0.01\end{array}$ & $\begin{array}{l}0.03 \\
\pm 0.01\end{array}$ & $\begin{array}{l}2.7 \pm \\
12.5\end{array}$ & $\begin{array}{l}0.03 \pm \\
0.01\end{array}$ & $\begin{array}{l}0.03 \\
\pm 0.01\end{array}$ & $\begin{array}{l}-2.3 \pm \\
10.4\end{array}$ & $\begin{array}{l}0.03 \pm \\
0.01\end{array}$ & $\begin{array}{l}0.03 \\
\pm 0.01\end{array}$ & $\begin{array}{l}5.3 \pm \\
14.5\end{array}$ & $\begin{array}{l}0.178 \\
(0.28)\end{array}$ & $\begin{array}{l}0.345 \\
(0.14)\end{array}$ & $\begin{array}{l}0.184 \\
(0.28)\end{array}$ \\
\hline Total & $\begin{array}{l}0.38 \pm \\
0.06\end{array}$ & $\begin{array}{l}0.36 \\
\pm 0.06\end{array}$ & $\begin{array}{l}-4.1 \pm \\
4.4\end{array}$ & $\begin{array}{l}0.41 \pm \\
0.06\end{array}$ & $\begin{array}{l}0.37 \\
\pm 0.06\end{array}$ & $\begin{array}{l}-7.5 \pm \\
5.6\end{array}$ & $\begin{array}{l}0.38 \pm \\
0.06\end{array}$ & $\begin{array}{l}0.36 \\
\pm 0.07\end{array}$ & $\begin{array}{l}-6.2 \pm \\
4.2\end{array}$ & $\begin{array}{l}0.561 \\
(0.16)\end{array}$ & $\begin{array}{l}<.001 \\
(1.09)\end{array}$ & $\begin{array}{l}0.139 \\
(0.31)\end{array}$ \\
\hline
\end{tabular}

(Footnotes for Table 4)

Values are mean \pm standard deviation. Bold indicates statistically significant. *: Difference compared with type $\mathrm{S}(P<0.001$, effect size $d=1.54)$ and type $\mathrm{SC}$ 0.001 , effect size $d=2.25)$. + : Difference compared with type C $(P=0.003$, effect size $d=1.34)$ and type SC $(P=0.018$, effect size $d=1.17)$. $¥$ : Difference compared with type SC (adduction, $P=0.003$, effect size $d=1.24$; internal rotation, $P=0.009$, effect size $d=1.02$ ).

A typical example of the waveform of hip joint moment during normal and fast gaits in each strategy type is described in Fig. 2. The peak values increased during fast gait as compared with normal gait for all hip moments (Table 4). Moreover, interaction effects were found in the external hip adduction and internal rotation moments, and the increase rate was significantly lower in type $\mathrm{C}$ than in type SC. Regarding the hip moment impulse, although no interaction 
effect was observed, a speed main effect was found in the frontal plane and total hip moment impulse. Those hip moment impulses were significantly decreased in the fast gait as compared to the normal gait.

\section{Discussion}

In this study, we investigated the effects of various strategies for increasing gait speed on hip pain and physical function in patients with hip OA and also examined the effects of strategies for increasing gait speed on changes in hip loading during gait. Most patients with hip OA were classified as type $\mathrm{C}$. Physical function status was higher in types $\mathrm{C}$ and $\mathrm{SC}$ than in type $\mathrm{S}$, which suggested that the strategies that included increasing cadence to achieve faster gait speed were associated with higher physical function scores. Type $\mathrm{C}$ had a lower increase in peak hip joint moments, particularly hip adduction and internal rotation moments, than type SC when the gait speed increased. These findings partially supported our hypothesis; however, no significant difference in hip pain was found between groups based on the strategy used for increasing gait speed. To our knowledge, no previous studies have reported strategies for making changes in gait speed or their association with physical function status in patients with hip OA.

Among patients with hip OA, the highest proportion (48.9\%) prioritized increasing cadence (i.e., type $\mathrm{C}$ ) to achieve faster gait speed. This was different from the results for healthy individuals, where most subjects were of type SC (40.3\%), followed by type C (32.7\%) [3]. The gait of patients with hip OA is characterized by a decrease in self-selected gait speed, mainly due to a decrease in step length on the affected side and in stride length [8]. Kinematically, decreased hip flexion/extension angle is a gait feature that can lead to a decrease in step and stride lengths [23]. Moreover, passive hip ROM was reported to be responsible for variance in hip angle during gait in patients with mild-to-severe hip OA [18, 24]. These findings may explain the reason why patients with hip OA tended to prefer to utilize the type $C$ strategy. However, interestingly, the hip ROM in type $C$ individuals was larger than that in type $S$ individuals. These results indicate that the choice of cadence-increasing priority strategy observed in type $\mathrm{C}$ was not a compensation for peripheral constraints such as ROM restriction, but was rather a more active choice of strategy with some advantage to the stride length-increasing strategy.

In type $\mathrm{C}$, the rates of increases in peak hip adduction and internal rotation moments tended to be lower than those in the other 2 types, particularly type SC. In 4 type $\mathrm{C}$ individuals, whose stride length decreased during fast gait, little change $(0.8 \%$ increase) in peak hip adduction moment was observed despite an increase in gait speed of $11.0 \%$. Increases in peak joint moments with increasing gait speed are known to be due mainly to the increase in stride length $[3,4,6$, 7]. In healthy individuals who used a cadence-increasing strategy, little change in hip moments was observed, except for parts of the hip flexion and adduction moments in transition from normal to fast gait [3]. The results of our study in patients with hip OA are consistent with these findings in healthy individuals. Even with the same gait speed, the anterior and posterior ground reaction forces increased when the stride increased and cadence decreased [25]. At this time, the magnitude of the vertical ground reaction force showed little change; however, the anterior and posterior inclinations of the ground reaction forces increased. Thus, changes in the magnitude and inclination of the anterior and posterior ground reaction forces cause an increase in joint moments [4, 25]. Therefore, preferential use of strategies that include increased stride length to increase gait speed would tend to increase hip joint loading.

Moreover, although no interaction was observed, the hip joint moment impulse (adduction and total) decreased during fast gait in all strategy types. The hip adduction moment impulse showed the smallest increase with increasing gait speed despite the magnitude being the largest in all 3 dimensions. Therefore, as a result of being more affected by the decreased stance time due to increased cadence, the hip adduction and total moment impulse may have decreased during fast gait. Recently, in knee OA, a lower cadence during gait (i.e., a longer stance time) has been reported to be associated with worsening of cartilage damage of the tibiofemoral and patellofemoral joints [26]. As the hip adduction moment impulse is a significant factor in generating the cumulative hip moments associated with the progression of hip OA [16], converting normal gait into fast gait over short distances might, in some cases, be useful for protecting the hip joint from degeneration.

Importantly, the physical function status was higher in types C and SC, i.e., types that involved increasing cadence, than in type S. The robustness of the results was confirmed in the sensitivity analysis, with alternative criteria of type classification. Given that increasing stride length contributes more to increasing joint load than increasing cadence, the priority of increasing stride length would increase mechanical stress on the hip joint and cause excessive energy consumption in the hip muscles in daily life and, consequently, may cause deterioration in physical function. However, no significant difference in physical function was found between types $\mathrm{C}$ and $\mathrm{SC}$, despite the markedly lower rate of increase in hip joint moments in type $\mathrm{C}$ than in type $\mathrm{SC}$. This suggests that the relationship between the changes in hip moment due to differences in strategies for increasing gait speed and physical function is not direct. Several factors, such as radiographic OA severity, hip and knee muscle strengths, hip flexion ROM, stiffness, and pain, are associated with deteriorating physical function in patients with hip OA [19,27 - 29]. In this study, the hip ROM tended to be larger in patients implementing type $C$ than in those implementing type S. Thus, the difference in physical function in patients with hip OA should be explained on the basis of multiple factors. However, it is noteworthy that the differences in physical function between the strategy types remained statistically significant, with a large effect size, even after adjustment for hip ROM in an additional analysis (type $S$ vs. type $C ; P=0.044$, effect size $f=0.43$ : type $S$ vs. type SC; $P=0.021$, effect size $f=0.66$ ). Moreover, differences in physical function remained significant after adjustment for gait speed (type $\mathrm{S}$ vs. type $\mathrm{C} ; P=0.014$, effect size $f=0.52$ : type $\mathrm{S}$ vs. type SC; $P=$ 0.002 , effect size $f=0.90$ ) or stride length (type S vs. type $C ; P=0.032$, effect size $f=0.46$ : type $\mathrm{S}$ vs. type SC; $P=0.003$, effect size $f=0.83$ ) during normal gait, indicating that the strategy for increasing gait speed is a factor that affects physical function independently of the characteristics of normal gait. Thus, this study provides evidence for an important finding regarding gait-related risk factors for physical function deterioration in patients with hip OA. The difficulty in increasing cadence when increasing gait speed may be associated with the deterioration of physical function. On the other hand, no association was found between hip pain and strategy type in increasing gait speed. Another study reported that hip pain was not associated with hip angle and moments during gait in patients with hip OA [30]. Moreover, in addition to peripheral mechanisms, the hypersensitivity of the central nervous system has been identified to be involved in OA pain [31]. Taken together, in the present study, hip pain was affected by several other factors, and variations in the changes in mechanical loading on the hip joint and hip pain may not necessarily be associated with each other. 
This study had several limitations that need to be acknowledged. First, hip joint force, which reflects the pattern of muscle forces during gait was not measured. However, because hip joint moments are strongly correlated to hip joint forces during gait [32], the hip joint moments were used as an index of joint load in this study. Second, although both normal and fast gaits were measured at the self-selected speed by the patient, gait analysis was conducted in a laboratory setting. Thus, the results of this study may not necessarily reflect the change in gait speed and related gait biomechanics in patients in real life. Third, hip pain may have been caused by activities other than walking, because the pain was not assessed during gait per se. Furthermore, patients with endstage hip OA were excluded with consideration of risks, such as worsening of hip pain and difficulty of the task. In addition, this study only included female patients because the patients who met the criteria had a sex bias (percentage of males: 6.9\%), similar to other studies [33]. Thus, care should be taken when generalizing these results to other patient populations. Finally, the cross-sectional design of this study makes it difficult to consider the causal relationship between gait strategy and hip pain and physical function. Further cohort and intervention studies are needed to establish the effects of gait strategies involving changes in stride length and cadence on hip loading, hip pain, and physical function in patients with hip OA.

Despite these limitations, the findings of this study provide a new perspective for gait analysis in patients with hip OA. Examining not only normal gait but also the strategies used for increasing gait speed would be useful in understanding the underlying adjustment mechanism during gait, which is related to hip loading. Furthermore, the strategies can be evaluated from stride length and cadence, which can be easily measured clinically. Moreover, therapeutic exercise has been reported to be able to increase cadence during gait in patients with hip OA and total hip arthroplasty [34, 35]. Therefore, evaluating and modifying the strategy to prioritize increasing cadence to change gait speed may contribute to the maintenance of a high physical function level.

\section{Conclusions}

The findings of this study provide a new perspective for gait analysis in patients with hip OA. The proportion of patients who mainly increased gait speed by increasing cadence (type $\mathrm{C}$ ) was highest among patients with hip OA. Type $\mathrm{C}$ individuals tended to suppress the increase in peak hip adduction and internal rotation moment with increasing gait speed. Moreover, type C and SC individuals, both of whom included increased cadence in their strategies, maintained higher physical function levels than type S, although their relationship was unclear. These results suggest that encouraging a cadence-increasing strategy for coping with changes in gait speed may be useful for reducing hip loading and maintaining and improving physical function in patients with hip OA.

\section{Abbreviations}

OA: Osteoarthritis; SF-36: Medical Outcomes Study 36-Item Short-Form Health Survey; mJSW: minimum joint space width; ROM: Range of motion; ICC: Intraclass correlation.

\section{Declarations}

\section{Ethics approval and consent to participate}

All participants provided informed consent, and the protocol was approved by the Ethics Committee of the Kyoto University Graduate School and Faculty of Medicine (protocol identification number: E1683).

\section{Consent for publication}

All participants signed the consent for publication.

\section{Availability of data and material}

All data analyzed in this study are included in this published article.

\section{Competing interests}

There are no conflicts of interest to declare with regard to this study.

\section{Funding}

This study was supported by the JSPS KAKENHI Grant-in-Aid for Scientific Research (B), Grant No. 17H02134.

\section{Authors' contributions}

All authors contributed substantially to the conception and design of this research. HT measured, analyzed, interpreted the data, and wrote the manuscript. NI interpreted the data and revised the manuscript. HA, KG, KS, and YK were responsible for patient recruitment and diagnosis. All authors read and approved the final manuscript.

\section{Acknowledgements}

We wish to thank all volunteers who took part in this study for their participation.

\section{References}


1. Alhajyaseen WKM, Iryo-Asano M. Studying critical pedestrian behavioral changes for the safety assessment at signalized crosswalks. Saf Sci. 2017;91:351-60.

2. Egerton T, Danoudis M, Huxham F, lansek R. Central gait control mechanisms and the stride length-cadence relationship. Gait Posture. 2011;34:178-82.

3. Ardestani MM, Ferrigno C, Moazen M, Wimmer MA. From normal to fast walking: Impact of cadence and stride length on lower extremity joint moments. Gait Posture. 2016;46:118-25.

4. Kirtley C, Whittle MW, Jefferson RJ. Influence of walking speed on gait parameters. J Biomech. 1985;7:282-8.

5. Riley PO, Croce UD, Kerrigan DC. Propulsive adaptation to changing gait speed. J Biomech. 2001;34:197-202.

6. Allet L, IJzerman H, Meijer K, Willems P, Savelberg H. The influence of stride-length on plantar foot-pressures and joint moments. Gait Posture. 2011;34:300-6.

7. McGrath RL, Ziegler ML, Pires-Fernandes M, Knarr BA, Higginson JS, Sergi F. The effect of stride length on lower extremity joint kinetics at various gait speeds. Plos One. 2019;14:e0200862.

8. Constantinou M, Barrett R, Brown M, Mills P. Spatial-temporal gait characteristics in individuals with hip osteoarthritis: A systematic literature review and meta-analysis. J Orthop Sports Phys Ther. 2014;44:291-303.

9. Bejek Z, Paróczai R, Illyés Á, Kiss RM. The influence of walking speed on gait parameters in healthy people and in patients with osteoarthritis. Knee Surg Sports Traumatol Arthrosc. 2006;14:612-22.

10. Takatori $\mathrm{Y}$, Ito $\mathrm{K}$, Sofue $\mathrm{M}$, Hirota $\mathrm{Y}$, Itoman M, Matsumoto $\mathrm{T}$, et al. Analysis of interobserver reliability for radiographic staging of coxarthrosis and indexes acetabular dysplasia: a preliminary study. J Orthop Sci. 2010;15:14-9.

11. Tateuchi H, Koyama Y, Tsukagoshi R, Akiyama H, Goto K, So K, et al. Associations of radiographic degeneration and pain with daily cumulative hip loading in patients with secondary hip osteoarthritis. J Orthop Res. 2016;34:1977-83.

12. Kosinski M, Keller SD, Hatoum HT, Kong SX, Ware JE Jr. The SF-36 Health Survey as a generic outcome measure in clinical trials of patients with osteoarthritis and rheumatoid arthritis: tests of data quality, scaling assumptions and score reliability. Med Care. 1999;37(5 Suppl):MS10-22.

13. Kosinski M, Keller SD, Ware JE Jr, Hatoum HT, Kong SX. The SF-36 Health Survey as a generic outcome measure in clinical trials of patients with osteoarthritis and rheumatoid arthritis: relative validity of scales in relation to clinical measures of arthritis severity. Med Care. 1999;37(5 Suppl):MS2339.

14. Reijman M, Hazes JMW, Koes BW, Verhagen AP, Bierma-Zeinstra SM. Validity, reliability, and applicability of seven definitions of hip osteoarthritis used in epidemiological studies: a systematic appraisal. Ann Rheum Dis. 2004;63:226-32.

15. Jacobsen S, Sonne-Holm S. Hip dysplasia: a significant risk factor for the development of hip osteoarthritis. A cross-sectional survey. Rheumatology. 2005;44:211-8.

16. Tateuchi H, Koyama Y, Akiyama H, Goto K, So K, Kuroda Y, et al. Daily cumulative hip moment is associated with radiographic progression of secondary hip osteoarthritis. Osteoarthritis Cartilage. 2017;25:1291-8.

17. Pua YH, Wrigley TW, Cowan SM, Bennell KL. Intrarater test-retest reliability of hip range of motion and hip muscle strength measurements in person with hip osteoarthritis. Arch Phys Med Rehabil. 2008;89:1146-54.

18. Tateuchi H, Koyama Y, Akiyama H, Goto K, So K, Kuroda Y, et al. Radiographic and clinical factors associated with one-leg standing and gait in patients with mild-to-moderate secondary hip osteoarthritis. Gait Posture. 2016;49:207-12.

19. Arokoski MH, Haara M, Helminen HJ, Arokoski JP. Physical function in men with and without hip osteoarthritis. Arch Phys Med Rehabil. 2004;85:574-81.

20. Perrot S, Poiraudeau S, Kabir-Ahmadi M, Rannou F. Correlates of pain intensity in men and women with hip and knee osteoarthritis. Results of a national survey: The French ARTHRIX study. Clun J Pain. 2009;25:767-72.

21. Veenhof C, Huisman PA, Barten JA, Takken T, Pisters MF. Factors associated with physical activity in patients with osteoarthritis of the hip or knee: a systematic review. Osteoarthritis Cartilage. 2012;20:6-12.

22. Cohen J. A power primer. Psychol Bull. 1992;112:155-9.

23. Meyer CAG, Corten K, Fieuws S, Deschamps K, Monari D, Wesseling M, et al. Biomechanical gait features associated with hip osteoarthritis: towards a better definition of clinical hallmarks. J Orthop Res. 2015;33:1498-507.

24. Baker M, Moreside J, Wong I, Rutherford DJ. Passive hip moment measurements related to dynamic motion during gait in hip osteoarthritis. J Orthop Res. 2016;34:1790-7.

25. Martin PE, Marsh AP. Step length and frequency effects on ground reaction forces during walking. J Biomech. 1992;25:1237-9.

26. Hart HF, Gross KD, Crossley KM, Barton CJ, Felson DT, Guermazi A, et al. Step rate and worsening of patellofemoral and tibiofemoral joint osteoarthritis in women and men: the multicenter osteoarthritis study. Arthritis Care Res. 2020;72:107-13.

27. Pua YH, Wrigley TV, Cowan SM, Bennell KL. Hip flexion range of motion and physical function in hip osteoarthritis: mediating effects of hip extensor strength and pain. Arthritis Care Res. 2009;61:633-40.

28. Steinhilber B, Haupt G, Miller R, Grau S, Janssen P, Krauss I. Stiffness, pain, and hip muscle strength are factors associated with self-reported physical disability in hip osteoarthritis. J Geriatr Phys Ther. 2014;37:99-105.

29. Hall M, Wrigley TV, Kasza J, Dobson F, Pua YH, Metcalf BR, et al. Cross-sectional association between muscle strength and self-reported physical function in 195 hip osteoarthritis patients. Semin Arthritis Rheum. 2017;46:387-94.

30. Zeni J, Pozzi F, Abujaber S, Miller L. Relationship between physical impairments and movement patterns during gait in patients with end-stage hip osteoarthritis. J Orthop Res. 2015;33:382-9.

Page $10 / 11$ 
31. Llunch E, Torres R, Nijs J, Oosterwijck JV. Evidence for central sensitization in patients with osteoarthritis pain: a systematic literature review. Eur J Pain. 2014;18:1367-75.

32. Wesseling M, de Groote F, Meyer C, Corten K, Simon JP, Desloovere K, et al. Gait alterations to effectively reduce hip contact forces. J Orthop Res. 2015;33:1094-102.

33. Nakamura J, Oinuma K, Ohtori S, Watanabe A, Shigemura T, Sasho T, et al. Distribution of hip pain in osteoarthritis patients secondary to developmental dysplasia of the hip. Mod Rheumatol. 2013;23:119-24.

34. Coulter CL, Scarvell JM, Neeman TM, Smith PN. Physiotherapist-directed rehabilitation exercises in the outpatient or home setting improve strength, gait speed and cadence after elective total hip replacement: a systematic review. J Physiother. 2013;59:219-26.

35. Fukumoto Y, Tateuchi H, Tsukagoshi R, Okita Y, Akiyama H, So K, et al. Effects of high- and low-velocity resistance training on gait kinematics and kinetics in individuals with hip osteoarthritis: a randomized controlled trial. Am J Phys Med Rehabil. 2017;96:417-23.

\section{Figures}

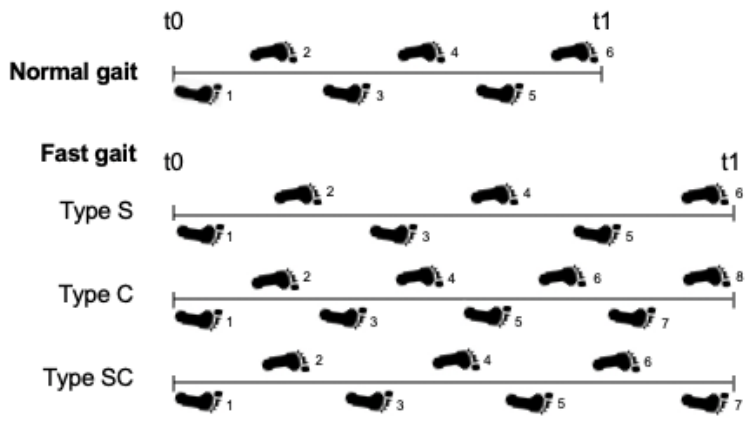

\section{Figure 1}

Schema of the change in each strategy type from normal to fast gaits. Type S mainly increases stride length; type C, cadence; and type SC, both stride length and cadence to increase gait speed.

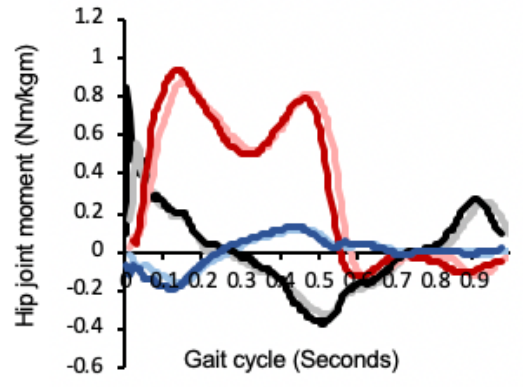

Type S

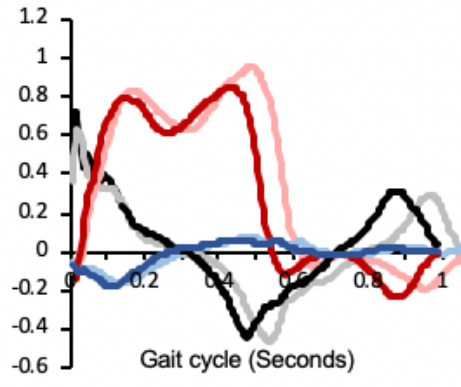

Type C

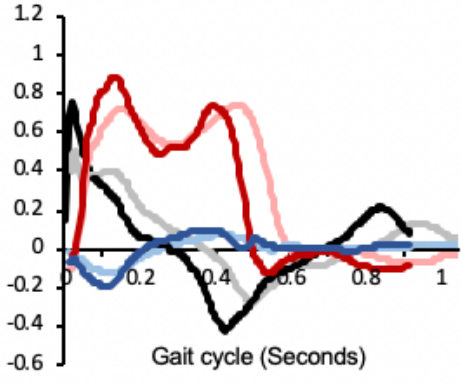

Type SC

Figure 2

Typical waveforms of hip joint moments in types S, C, and SC. Black, red, and blue lines indicate external hip flexion/extension, adduction/abduction, and external/internal rotation moments during gait, respectively. Lighter colors of each represent normal gait, and darker colors represent fast gait. In types $C$ and $\mathrm{SC}$, cadence is increased (i.e., stance phase time is decreased) in fast gait, and waveforms are specifically compressed on the left side in fast gait than in the normal gait. 